
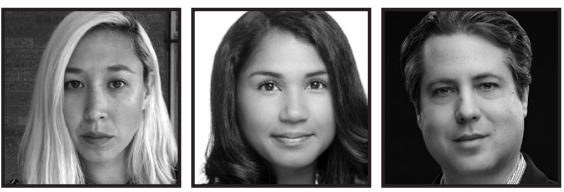

\title{
"Beyond the Barriers": Listening to Immigrant Youth to Transform Higher Education
}

\author{
Grace D. Player, Victoria S. Gill, and Gerald Campano, \\ University of Pennsylvania Graduate School of Education
}

\begin{abstract}
This article explores the ways a university-based research team learned with and from immigrant youth as they collaboratively inquired into issues surrounding access to higher education. Through a close look at the youth's research, including their discussions and written texts, we examine their desires for higher education and their responses to visiting our campus. We found that the students began to develop both a sense of belonging to higher education and a healthy skepticism of its admissions practices and institutional representation. They were also able to conceptualize their identities, at least in part, as assets to the college application process. From this study, we draw implications for fostering more equitable university-community partnerships.
\end{abstract}

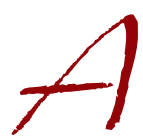

group of nine middle and high school students of Indonesian and Mexican descent walked together through our university library on a guided tour. The youth, members of a yearlong group inquiry into college, ran their fingers over the lengths of bookshelves and peered in awe at the classrooms laden with the newest technology. They observed tables full of undergraduate and graduate students at work in the brightly lit rooms, MacBooks and iPads open before them, sipping lattes from the in-house café. Angelo shook his head, laughing, "This is madness!" Lei added, "When I come here, I don't need a dorm room. I'll just live here." The youth were surprised by and lingered in the overabundance of creature comforts, which they had not realized existed behind the stone walls of the historic buildings. 
The ambivalence the students felt toward higher education was striking in this moment. Our university is less than three miles away from most of their homes and schools, yet in some respects, it seemed worlds away. The social distance between the youth's neighborhoods and the university was not a result of a lack of aspiration or academic ability on the part of the students and their families. Rather, it was in part constructed by the exclusionary nature of higher education for students from historically disenfranchised backgrounds, the uneven distribution of Pk-12 resources, and false assumptions about who "belongs" at elite universities. Angelo and Lei's exclamations in response to the extravagance of the library suggested their awareness of the very real class borders between the predominantly white university with a \$10.1 billion endowment and their multiethnic immigrant and working class neighborhood. This awareness sat uneasily alongside their yearning for the intellectual and social opportunities of higher education.

Throughout The College Inquiry, our collaborative research into the college experience and college access, the immigrant youth discussed their hopes, questions, and concerns. We believe that by engaging in sustained inquiry with youth, we can become privy to their perspectives about educational inequities, and also build and maintain bridges between two seemingly disparate worlds. Our project sought to move beyond simple "outreach" and toward fostering reciprocal partnerships that enable students to learn about and potentially see themselves as part of the university from early on. It is with knowledge developed through participatory research with youth and their communities that we can reimagine higher education as more welcoming and accessible to all.

Alongside youth, we investigated the following question: What happens when first-generation students of color are invited to inquire into and make sense of higher education? In this article, we trace three major thematic findings: how students already possessed a nuanced understanding of their own higher education desires and needs; how, through their inquiries, they developed both a sense of belonging and a healthy skepticism of the systems they observed; and how they conceptualized their identities, at least in part, as assets to the college application process. Taken together, these themes reveal the potential for cultivating genuine and reciprocal partnerships in the service of educational equity. 


\section{Background/Story of the Question}

The College Inquiry was part of a larger partnership between a university research team and the community at St. Frances Cabrini, a multilingual and multicultural parish and community in Philadelphia. The larger partnership, led by Gerald, has been ongoing for six years and investigates how community members use language and literacy to negotiate a shared vision of educational justice and immigrant rights across linguistic, cultural, and institutional boundaries (Campano, Ghiso, \& Welch, 2016). The partnership draws on ethnographic (Erickson, 1986), participatory (Cahill, 2007; Kemmis \& McTaggart, 2005), and practitioner research methods (Cochran-Smith \& Lytle, 2009) in ways that forefront transparency and reciprocity.

The College Inquiry included nine youth, ages 12-18; eight were Indonesian and one was of Mexican descent. The topic of college access was identified as a major concern in previous studies in the partnership (see Campano, Ghiso, Rusoja, Player, \& Schwab, 2016; Player, Ngo, \& Campano, 2016). It was also informed by ongoing conversations we were having with families from the respective cultural and linguistic communities at the site, who argued that access to a high-quality education should be a "human right," irrespective of one's immigration or economic status (Campano et al., 2016). Over time, students' questions and concerns about higher education were a recurring topic. In the spirit of designing research based on participants' stated needs and desires, Grace took the lead on facilitating a more formal inquiry into college admissions.

Within the inquiry itself, Grace and several master's students designed the College Inquiry, which incorporated opportunities for students to generate and research questions about access and the college experience. Victoria joined the group halfway through the year, helping to plan and implement lessons based on her personal experiences as a first-generation American and college student of color and as the founding director of a college preparatory program serving minoritized students. The youth formed inquiry groups around the issues they'd chosen (e.g., financial aid, SAT/ACTs, scholarships, student life) and then pursued those questions by searching the Internet, interviewing community members and college students, drawing from personal knowledge, visiting the campus, and representing their work multimodally. 


\section{Methodology}

Part of our research stance involves challenging the all-too-rigid researcher/ researched binary that hierarchizes university over community knowledge (Cochran-Smith \& Lytle, 2009; Smith, 2012). As Cynthia Dillard (2000), among others, argues, relational work is often seen as disrupting the assumed "neutrality" of research. She advocates, by contrast, for research that "maintains allegiance and substantive connections to the very communities under study" (p. 662). We believe this is a more ethical approach to research that sees participants as fully human in their intellect, knowledge, emotion, and complexity.

For this project, we draw from Campano, Ghiso, and Welch's (2015) norms for carrying out community-based research, which were developed as part of the overall partnership. These methodological practices are in the service of building a sustainable and trusting long-term research collaboration. Our approach to research views community members as research partners and strives to learn from and with them through an activist stance (Simon, Campano, Broderick, \& Pantoja, 2012). We believe that community-based research that values the knowledge already present in communities (Campano, 2007; Moya, 2000) yields access to information otherwise obscured by more distant methodologies and enacts more "humanizing" (Paris \& Winn, 2014) research relationships. We contend, like Paris (2011), that "genuine and honest sharing led to richer and truer data than the model of the somewhat detached, neutral researcher that echoes across the decades from more positivist-influenced versions of qualitative inquiry" (p. 139).

Our approach to research also centers on identity and experientially based knowledge, honoring community members and youth as "cosmopolitan intellectuals," theorists and agents of change who have unique vantage points from which to interpret and generate knowledge about the world (Campano \& Ghiso, 2011). This knowledge is derived from their intersectional experiences in navigating day-to-day injustices and engaging in social activism, what scholars have referred to as their "epistemic privilege" (Campano, 2007; Mohanty, 1997; Moya, 2000). We believe that it is marginalized people who are uniquely positioned to understand oppression and to theorize change (Collins, 2008).

We draw from practitioner inquiry (Cochran-Smith \& Lytle, 2009) and participatory action research methodologies (Cahill, 2007; Kemmis \& McTaggart, 2005) that center the perspectives, experiences, and goals of community members and that aim 
toward shared decision making and knowledge production. Ethnographic methods help to further situate what's happening at the site within broader dynamics and to account for the range and variation of perspectives from university-based researchers and youth. Researchers kept fieldnotes and memos in order to capture moments and trends and to engage in on ongoing analysis throughout the project (Emerson, Fretz, \& Shaw, 1995; Maxwell, 2013). Additionally, we collected data from semi-structured interviews, group artifacts, and audio-recordings of sessions so that we could analyze at the level of interaction (Bloome, Carter, Christian, Otto, \& Shuart-Faris, 2005) how students were engaging in the inquiries.

These methodologies are not without their own challenges. The collaborative research model requires investments of time, labor, and relationships that are often in tension with the pace and organization of educational contexts, including the academy. The emergent curriculum of the club necessitated that our planning be dialogic and respond to the questions and concerns of the youth as well as our own evolving insights. Much of the College Inquiry took place beyond the boundaries of our "official" meeting times, demanding an emotional investment as well as hours put into texts, phone calls, and informal meet-ups. Such relational labor can be perceived as peripheral to research in academic contexts, rather than part of the research process itself, thus leading to undervaluing or potentially curtailing this necessary dimension to collaborative inquiry. Furthermore, depending on the context, educational policies intended to protect student participation, such as delineating when and where educators and youth can communicate, may not align with the fluid ways in which adolescents use digital literacies (such as social media or texting) to communicate with others. Trust and permission to communicate with youth outside of the club was likely granted as a result of the goodwill built over time between facilitators, parents, and parish leadership. We had been collaborating with this small group of youth and their families over the course of nearly three years-a project which began based on families' requests for educational experiences for their children. In order to cultivate the conditions for participatory work, we had to intentionally protect the deliberate and measured pace of the research. Educators don't necessarily have such a stretch of time and concentrated attention with students and families, yet these were invaluable in the collaboration. It is a reminder that the investments and complications of participatory inquiry are part of the work, and that they can help us create practices of research that are more responsive to the lived experiences and expressed desires of participants.

It is also important to note that the youth's observations and insights are not meant to be generalized to other groups, or even the wider St. Frances community, 
but instead to serve to point to the ways knowledge can be generated in universitycommunity relationships. In the section that follows, we discuss the three main themes we identified through our analytic coding (Strauss \& Corbin, 1998).

\section{Findings}

\section{"A Place Where I Feel Comfortable and Safe": Imagining College}

Through our collaborative inquiry with the youth we learned that they wisely predicted what might bring about their success in higher education. What we found was that students desired not only strong academics and preparation for eventual careers, but also safety and a sense of belonging. This aspiration was evident from one of the first days of the inquiry, when we asked students to write reflective memos about their hopes, anxieties, and questions in regards to college. Throughout the activity, Grace meandered through the group, sitting with students and talking with them about their thoughts and sharing some of her personal experiences in college, including the freedoms and challenges of being away from family. Students then gathered in small groups to discuss with each other their wonderings, dreams, and fears about college. Some of their responses included:

- My ideal college for me is a place where I feel comfortable and safe. I want to go to a school where I can ask for help and not feel judge. My hopes for college is that I get into a good college.

- My hope is to find a college that have a safe environment, many respectful people and professors who able to give/help us preparing for our future jobs.

- Ideal Experience: Medium-large size campus; large amount of students depending on campus size; location doesn't matter; not too strict dorm rules (mostly noise-wise); Decent sized rooms (not too cramped); clean dorms and restrooms (preferably private showers); large variety of clubs (even though I probably won't join them)

- Anxieties: ....Not being accepted into the community

- To have a wonderful learning and a good time in college. My hopes are to learn and grow my knowledge seed to help me be successful with my future job.

- What will my life outside of classes be like?

- What else can I do to be involved?

- How does it feel to be in college? 


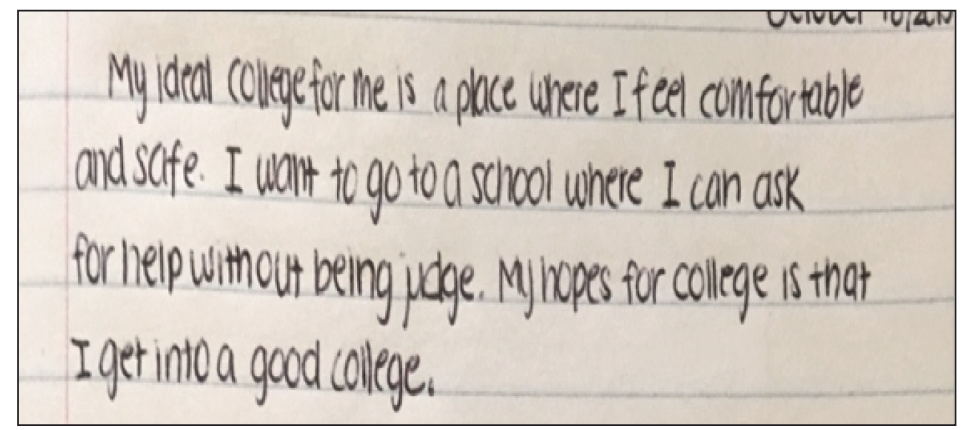

Fig. 1: Evey's description of the ideal college

Students' writings and conversations repeatedly invoked words and phrases related to their sense of well-being. The need for "safety," respect," and "acceptance" animate both the academic dimensions of college ("respectful professors" who help prepare youth for future employment opportunities) as well as the social and cultural spheres of campus life such as extracurricular clubs and comfortable living arrangements. Their concerns also centered the notion of acceptance. Our analysis suggests that students understood that their college experience would be affected not just by the quality of academic programs, but also by a sense of being welcomed and feeling part of the college space. The youth's writing point to what many higher education scholars have asserted: that a sense of belonging, support, and involvement correlates with academic success. This is especially true for first-generation and minoritized college students on the campuses of predominantly white institutions where they may come into contact with frequent racism including stereotyping and racial conflict (Dennis, Phinney, \& Chuateco, 2005; Harper, 2015; Petty, 2014; Terenzini et al., 1994).

We speculate that the students were able to identify what higher education research has shown to be necessary for college success because of their own marginalized positionalities. The youth often reported feelings of being misunderstood in their school contexts because of their minoritized identities. For example, Matthew quietly admitted to Victoria that his greatest anxiety about college is "being put in a category by some people...like right now...especially some white people, they're like, they put people in categories in my school" (personal communication, July 16, 2016). Matthew draws on his racialized experiences "right now" to hypothesize that such stereotypes may persist in his future college experience as well. It's important to note that at St. Frances, Matthew is part of a tight-knit Indonesian community that provides him with significant support and social capital (Yee, Mostafa, \& Campano, 2016). One can imagine how feelings 
of educational discrimination and isolation might become compounded when he attends a university socially and physically distant from his neighborhood.

Matthew was not alone in his sense of being miscategorized in school. Students reported multiple incidents when they felt their Asian identities were not understood by their peers and teachers. In fact, the students discussed that most people don't even know anything about Indonesian people. Evey claimed:

Like the other people I tell, they're like, "Oh, are you, are you Vietnamese?" I'm like, "No, I'm Indonesian." They're like, I know like in the back of their faces, you see, like, they don't know what Indonesian is....So that kind of irritates me, so I feel like, "No, I'm Asian." That's the most easiest answer...Because it's a lot of explaining to do and people like, "Oh, there's a country called Indonesia?" I'm like, "Yea, it's, it's an island off the coast of like Australia and Malaysia." (personal communication, April 17, 2016)

Evey's comment reflects what Harper (2013; Harper, et al. 2011) terms "onlyness," describing "the psychoemotional burden of having to strategically navigate a racially politicized space occupied by few peers, role models, and guardians from one's same racial or ethnic group" (Harper et al., 2011, p. 190). While these students may be lumped with other Asians in their school contexts, Evey's reflections indicate a feeling of frustration with cultural erasure, one that would likely increase in a college experience further removed from the St. Frances Indonesian community.

Aria also pointed to instances when monolithic identity categories have led to misunderstandings. She explained that at times teachers talk about Asians "in a positive way," (personal communication, April 17, 2016) but also treat students according to the stereotypes they hold about different Asian ethnicities. Aria identifies strongly as Indonesian and claims not to identify with the dominant Asian group of Chinese students. She explains that she may have some Asian features, but she has a darker complexion, which in her experience causes teachers to stereotype her as Cambodian and have lower academic expectations of her than they have of students of Chinese heritage. Evey relates how she could benefit from academic support and more attention from her high school educators, a need which she feels is overlooked because as an Asian student, her teachers expect her to fend for herself. The youth's experiences align with Stacey Lee's (2009) finding that "Southeast Asian students, particularly Hmong, Cambodians, and Lao are often stereotyped by teachers as gangsters and held to low expectations" (Lee, 2005; Um, 2003 as cited by Lee, 2009, p. 14). Teachers have "low expectations" of Aria 
and Evey, and yet, conversely, expect them to succeed on their own because of their Asian backgrounds.

Students' narrations of their experiences with racism in school reflect educational scholars' findings that, too often, Asian American students are subject to stereotypes like the "model minority myth," which also serves to conceal the systemic inequities they face in college. The model minority myth portrays "Asian Americans as exemplary minorities who gain success through sheer effort and determination" (Lee, 2009, p. 7). Although a global look at data on Asian Americans paints a picture of success and prosperity in the United States, disaggregated metrics on Asian Americans reveals the ways the system is failing many youth. For instance, while approximately $44 \%$ of Asian Americans, as compared to $24 \%$ of the overall American population, hold bachelor degrees, 60\% of Hmong Americans and $50 \%$ of Laotians and Cambodians held less than a high school degree. Hmong Americans have the lowest rates of achieving bachelor's degrees at just $4 \%$ of the population (Goodwin, 2010). For Indonesian Americans, the data is murky because of several factors. First, the relatively low numbers of Indonesian Americans in most cities obscures them from official census data (U.S. Census Bureau, 2011). Further, Cunningham (2008) estimates that about 25,000 Indonesians have undocumented status, as compared to a total of 70,096 documented Indonesian Americans (U.S. Census Bureau, 2012), and thus, a large proportion are excluded from reported data. As a result, the experiences of Indonesian Americans are largely erased from the narrative about Asian Americans (Campano, Ngo, \& Player, 2015), as reflected by Evey's comments. The reports from David, Evey, and Aria reveal the importance of listening and learning from students about the complexity of Asian experiences and how to create safer, more understanding educational spaces for them.

One way we worked to create these spaces was through our reflexive and relational research process. We crafted lessons in ways we felt would make students feel safer in discussing challenging issues. Part of our dialogic pedagogy involved sharing about our own minoritized identities. For instance, Grace, from the beginning of the College Inquiry meetings, often referenced how her own identities as a Japanese-American woman and daughter of a Japanese-Brazilian immigrant had affected her educational experience. Further, in sharing her beliefs in social justice causes, for example, around Asian-Black alliances, she was openly reflexive about the ways her mixed-race East Asian identity both advantaged and disadvantaged her in the United States context. Victoria talked with the youth about her multiple identities, including being a female, first-generation biracial 
Laotian/Indian American and college student, and coming from a low socioeconomic background, as well as the constant struggle of finding her place within historically white institutions and universities.

Importantly, the inquiry community embodied the ethos of mutuality and support that students desired from their future universities. Aria, in describing the College Inquiry group, claimed, "it feels like we are hanging out and trying to improve ourselves together, it doesn't feel like a club, but more like helping each other out." Her claim of "improving ourselves together" [emphasis added] through "helping each other" stands in contrast to some of the negative experiences the youth recounted about other educational contexts. These are the sorts of collaborations that college students are trying to reproduce in spaces like the Asian American and Latinx cultural groups on campuses. One of the advantages of university-community partnerships is the opportunity for youth to connect to university students from similar backgrounds through reciprocal visits that set the relational foundation to access these types of resources in the future.

\section{“What's Really Going On": Youth's Skepticism Toward Access and Diversity on Campus}

A major component of the College Inquiry was a visit to our university. This visit was designed to help students visualize themselves on campus and imagine possibilities for higher education. As described above, the students were aware, based on their experiences, that obstacles might lie ahead for them as first-generation and minoritized students. We created a schedule for the visit that attended to both what students directly stated as their "must-sees" and what we thought might be beneficial to them. The places we visited included: academic, professional, and cultural organizations; various departments and schools on campus; the admissions and financial aid offices; the campus sports facilities; and a fraternity. Although the students did not specifically request visiting the cultural groups, the association for low-income first-generation students, or the learning resources center, we wanted to be sure to expose them to these aspects of campus that are typically less highlighted on marketing brochures or official tours-a decision in part informed by our own identities. For Victoria, having "made it" to a university did not automatically guarantee success, but in fact led to a new kind of struggle due to her lack of familiarity with the tools and resources available to help students remain in and succeed at college. For her, academic support programs and cultural centers offered a sense of belonging, for such organizations outside of lecture halls provided a different kind of education-one of navigating college in order not just to survive, but to thrive. 
To gain a firmer understanding of the sense students were making of higher education, we analyzed their reactions to the visit on the day itself as well as in subsequent conversations. We found that students had ambivalent feelings about life on college campuses. They were heartened by the possibilities, but were also aware that the university is not the utopia presented in fancy websites and glossy brochures-as Matthew commented, "I didn't see what I expected in the college." On the one hand, youth indicated that they felt that an elite university was, indeed, a place where they could belong. The current students we met were almost all students of color, including Asian, Latinx, and first-generation college students. This helped the youth to locate themselves with the university. Lei said of the visit, "It's beyond the barriers, here we get to talk to people and see what's really going on." The university students shared their own stories of overcoming obstacles, which inspired many of the youth to view college as a place where they belonged. The parents who joined us for the visit also mentioned their growing sense of accessibility to college. "What I learned today," said Angie, Evey's mother, in a visit to Gerald's class at the education school, "is that I thought it was hard to get into college, but now I know that it'll be okay" (fieldnotes, March 24, 2016).

However, the data also revealed that a healthy skepticism permeated students' perceptions of higher education. Evey complicated her mother's reaction to college admissions, claiming in a reflective conversation after the visit, "I don't like that the admissions officer told us there wasn't really a cut off for the SAT" (fieldnotes, April 3, 2016). Her comment was in reaction to the admissions officer telling the students that they all had a chance to get into the university regardless of test scores because the institution takes a holistic approach to admissions. On the day of the visit, the admissions officer spoke extensively about admissions being need blind, and when the youth and their parents asked questions about applying as immigrant students, she maintained a neutral stance. She reported that immigration status was not an issue as long as you were a permanent resident, which felt exclusionary to some of the mixed-status families. She did not mention the potential systemic difficulties students might face as immigrant students, but instead, expressed that the university would welcome students no matter what their background. It seems the officer was trying to create an image of the institution as unequivocally accepting, a place where all students belonged. Evey told the inquiry group that she felt that this was dishonest. Evey seemed to intuit Sara Ahmed's (2012) claims that schools might create images of "diversity" that obscure the overwhelming homogeneity that actually exists among students. Is there genuine class diversity on campus? How many students who are undocumented or from mixed-status families have the opportunity to attend and thrive? Does the representation of Asian-American 
students on campus include significant numbers of, for example, Indonesian, Filipino, and Lao youth? Do the types of activities that may give you a competitively holistic admissions profile, such as music lessons or science camps, require substantial economic resources or high-profile social connections? The discrepancies between the rhetoric of diversity and inclusivity and the realities of persistent inequities were not lost on the youth.

The youth also realized that access was not enough. Evey reflected on a comment made by a young woman at the Latinx cultural group, about not feeling safe on campus as a person of color. She emphasized how much this bothered her, shaking her head, saying she expected that the university would be a great place where you could speak your mind and feel safe about it. Evey mentioned also being concerned about the segregation of the cultural groups on campus. She explained that at her very diverse high school, she never has belonged to a group of just Asians:

Like me and my friends are a little bit darker than most of the other Asians. Like because they are really, really light, so like, I guess they group themselves together into like K Pop groups or whatever...But like me and my friends, I guess we don't really like those types of stuff, but like, there's a lot of, like people like Cambodians and stuff, they don't really like K-Pop so that's probably why I hang out with them. But we prefer like trap music or like stuff like that, so yeah... I think that's why I kind of get along with more like the African Americans and the Hispanics more than um, Asians, because it's not I don't really have that much common with them, even though I am Asian. I consider myself Asian, but they probably won't. (personal communication, April 17, 2016)

The visit to the cultural groups and Evey's reflections on it nod to the complex ways that minoritized students must often navigate predominantly white institutions, especially when they do not reflect the same diversity of students' high schools and neighborhoods. In the context of immigration, Evey experienced a racialized hierarchy within the Asian American community in her high school, which prompted her and her peers to establish affinities with other minoritized groups, in part mediated by a shared popular culture. The hybrid and intersectional realities of her social world did not quite map on to the categories and divisions of the university. Evey's reflections indicate the importance of institutions taking a close look at how they create safer spaces for all students of color and how to cultivate solidarity across difference. Universities also ought to see nuances and complexities of experience within groups. One source of frustration for us as researchers is that in our institution Asian Americans are not considered under-represented. This ignores 
the lived realities of social class, immigration status, and colonial legacies that continue to affect youth like Evey.

By listening to students, we see that they are attuned to the shortcomings of institutions that tout efforts toward diversification while still remaining predominantly white. Aria pointed directly to a felt lack of diversity she had observed in higher education when she asked, "Why is everyone so white?" after observing the photos on many college websites (fieldnotes, June 19, 2016). As her previous comment about her high school suggests, the majority of Asian Americans on campus did share her own experiences. The ostensible "over-representation" of Asian Americans obscures class difference and particular groups' immigration histories. Across the college inquiry, students came to understand that schools make efforts toward accepting and nurturing diverse student bodies as well as the shortcomings of these initiatives. What the college visit and subsequent conversations revealed is that students are aspirational about college while also critical of higher education. Universities might learn from students' hopes and critiques in order to create more equitable and nurturing spaces for them on campus.

\section{Investigating Identity for College Essays}

While youth's identities came up organically as they discussed college access, during the final stage of the project, it became an explicit topic of study through activities such as watching videos explaining the concept of intersectionality, taking part in a privilege walk, creating personal identity maps, and focused conversations. These pedagogical invitations enabled the youth to inquire into how one's race, gender, citizenship status, and religion shape one's educational and life opportunities (focus group interview, June 5, 2016). As they did this work, they simultaneously began the process of brainstorming and drafting ideas for their college essays. We purposely planned this juxtaposition between identity work and college essay writing to communicate to the youth that their experiences are an asset in seeking college admission. In order to demystify the process, Grace and Victoria made consistent efforts to model how they drew on their own racialized and gendered experiences to link with many universities' stated value of pluralism. The youth listened in and watched as Grace and Victoria created identity maps. Grace discussed the ways her mother's Japanese-Brazilian heritage clashed with her father's Anglo-American identity, and the dissonance this caused in her own developing self-understanding as a young person. She also narrated how this hybrid cultural legacy gave her unique insight into racism and sexism in the United States. Victoria delved into her emotional experiences of being torn between various 
cultures, languages, and religions. Despite social rejection, she nonetheless was able to claim the multiplicity of her experiences as an epistemic and creative strength. Gerald has shared with the youth and families over the years how education could potentially become a vehicle for self-determination and empowerment. Despite being tracked out of higher education, his Filipino-American father was able to attend university later in life on the G.I. Bill after serving in the military. This openness of the university researchers seemed to sanction spaces for the youth to consider how their own unique experiences would add to the intellectual culture of any university lucky enough to have them.

Aria developed the following approach to essay writing: "Using what I've experienced I will put all my emotions and thoughts into the [college] essay to create something unique." She continued, "You have to describe the world you come from, you gotta tell them what happened throughout your years and how it made you what you are, and your background" (personal communication, July 17, 2016). She demonstrates an understanding that colleges ought to value her unique insightsinsights derived from her multiple worlds and what she's endured. Although the students didn't use the term "epistemic privilege" (Moya, 2000), it seemed that they were beginning to understand that their experiences gave them specific knowledge about social inequality that may be less available for those from the dominant culture and class. Matthew described this phenomenon in an interview. He claimed, "they [some white school peers] used to leave me out of stuff, and yeah...so I don't think they understood how it felt to be discriminated" (personal communication, July 17, 2016).

Pablo, who is Mexican American, demonstrated how he drew from his family's experiences in his college application process while remaining critical of political discourses around Mexican immigration. He identified his parents' border crossing and "how they had to work" as important aspects of who he is (personal communication, July 17, 2016). At the same time, he expressed concern about being "in danger" because of Donald Trump (see Figure 2). Pablo speaks back to pernicious stereotypes, too often perpetuated by politicians and the media (Kristoff, 2016), and instead claims his family's immigration history as a source of pride and inspiration. In his identity map, Pablo also claims his spirituality, his multilingualism, the dignity of his humanity, and his connection to his elderstogether they reflect what Ghiso (2016) has identified as an "ethos of interdependence through everyday social practices" (p. 5). It is not surprising to us that Pablo would soon garner attention as a well-known activist in the immigrant rights movement, despite his skepticism of mainstream politics ("not interested in politics", Fig. 2). 
Even though we anticipate Pablo will be the first in his family to attend college, he nonetheless has a strong foundation in social justice education from his parents and his community. Through inquiry into the specificities of what they bring, the youth realized that they didn't necessarily have to conform to a universal image of what it means to be a scholar, nor did they have to compromise their cultural values or social commitments in order to package themselves as "ideal college students" in the admissions process. Hopefully, the universities to which they apply will recognize their brilliance. It's been the contention of this article that is more likely to happen if universities have sustained partnerships with communities over time.

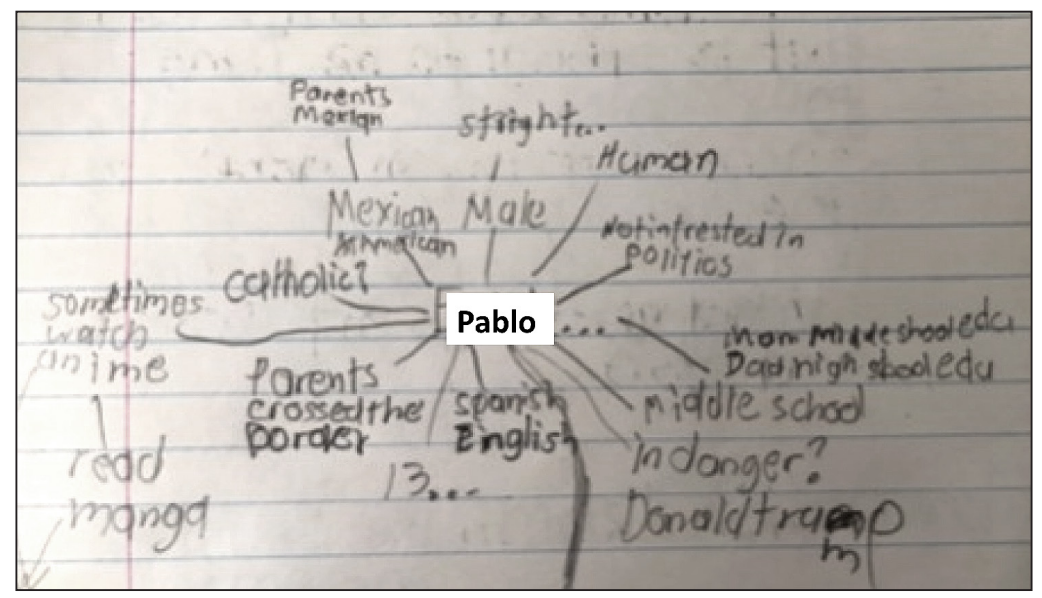

Fig. 2: Pablo's identity map

\section{Implications for University-Community Partnerships}

During our university visit, Lei joked about setting up camp in the library, with all it had to offer. The building's allure was not only its plentiful material resources, but also all the knowledge and possibilities these represented. How do we best honor Lei's aspirations? How do we support, from an early age, Lei's path to higher education? How do we ensure that once she is at the university, she feels a sense of belonging and thrives intellectually and emotionally?

We call on colleges and universities to listen to youth who are faced with structural barriers to higher education. The knowledge produced by The College Inquiry suggests that colleges and universities create sustained partnerships with youth and families. These partnerships would serve as mechanisms to tap into community knowledge, questions, and concerns about college, and to develop 
more inclusive and responsive campus cultures. Just as students would learn to adjust to higher education, colleges and universities would transform to better accommodate youth's social and cultural worlds. Fostering mutually edifying relationships and collaborations challenges assumptions about both what students bring (or "lack") as well as the nature of institutions.

Based on our findings, we propose some principles for university-community partnerships. Above all, these affiliations must be built on long-term, sustained relationships that seek to foster trusting and reciprocal exchanges of knowledge. A primary focus of partnerships should be creating environments that support students' agentive tendencies toward coalitional social justice work. At the same time that institutions of higher education cultivate opportunities to work alongside youth and families, it is also essential that they take a critical look at their policies, noting whether efforts to diversify their campuses go beyond static labels and categorizations and cultivate connections across cultural and class boundaries. Collaborating with community leaders, families, and neighborhood organizations can help universities learn about the funds of knowledge minoritized students bring with them to college classrooms, and how to best honor these resources in campus life, academically and socially. When universities listen and learn from and with youth, we can work, as Aria claimed, toward "improving ourselves together."

\section{Conclusion}

As part of a larger university-community partnership, the College Inquiry directly addressed a concern of parents and youth with whom we have been collaborating with over six years. Our practitioner research stance "is not just about discerning patterns...or developing conceptual models, but ultimately prioritizes creating the conditions for student flourishing" (Simon et al., 2012, p. 21). By engaging in intentional and sustained dialogue over time and creating opportunities to learn from and with one another, we sought to both demystify the college admissions process as well as to critically interrogate institutions of higher education. Our research underscores that youth know much of what they would need to thrive in college, possess a healthy skepticism that helps them critique recruitment information, and can mobilize their identities and community wealth as they apply to college. These findings suggest that university-community partnerships could have a significant impact on the experiences of incoming students from historically disenfranchised groups. Rather than "outreach" to "disadvantaged" groups, these types of partnerships would cultivate long-term relationships with families and many opportunities to build bridges and go "beyond barriers" in not just getting to college, but flourishing there. 


\section{Acknowledgment}

We would like to thank María Paula Ghiso for her feedback on drafts of this article.

\section{Note}

1. Student writing and talk is in their own words and was not edited by the authors of the article. All names are pseudonyms.

\section{References}

Ahmed, S. (2012). On being included: Racism and diversity in institutional life. Durham, NC: Duke University Press.

Banks, J. A. (2012). Encyclopedia of diversity in education: First-generation college students. Sage.

Bloome, D., Carter, S. P., Christian, B. M., Otto, S., \& Shuart-Faris, N. (2005). Discourse analysis and the study of classroom language and literacy events. Mahwah, NJ: Lawrence Erlbaum.

Cahill, C. (2007). Repositioning ethical commitments: Participatory action research as a relational praxis of social change. ACME: An International Journal of Critical Geographies, 6(3), 360-373.

Campano, G. (2007). Immigrant students and literacy: Reading, writing, and remembering. New York: Teachers College Press.

Campano, G., \& Ghiso, M. P. (2011). Immigrant students as cosmopolitan intellectuals. In S. Wolf, P. Coates, P. Enciso, \& C. Jenkins (Eds.), Handbook on research on children's and young adult literature (pp. 164-176). Mahwah, NJ: Lawrence Erlbaum.
Campano, G., Ghiso, M.P., Rusoja, A., Player, G., \& Schwab, E. (2016). "Education without boundaries": Literacy pedagogies and human rights. Language Arts, 94(1), 43-53.

Campano, G., Ghiso, M. P., \& Welch, B. (2015). Ethical and professional norms in community-based research. Harvard Educational Review, 8(1), 29-49.

Campano, G., Ghiso, M. P., \& Welch, B. (2016). Partnering with immigrant communities: Action through literacy. New York: Teachers College Press.

Campano, G., Ngo, L., \& Player, G. (2015). Researching from buried experiences: Collaborative inquiry with Asian American youth. LEARNing Landscapes, 8(2), 77-94.

Cochran-Smith, M., \& Lytle, S. L. (2009). Inquiry as stance: Practitioner research for the next generation. New York: Teachers College Press.

Collins, P. H. (2008). Black feminist thought. New York: Routledge.

Cunningham, C. E. (2008). Unity and diversity among Indonesian migrants to the United States. In $\mathrm{H}$. Ling (Ed.), Emerging voices: Experiences of underrepresented Asian Americans (pp. 90-108). New Brunswick, NJ: Rutgers University Press. 
Dennis, J. M., Phinney, J. S., \& Chuateco, L. I. (2005). The role of motivation, parental support, and peer support in the academic success of ethnic minority first-generation college students. Journal of College Student Development, 46(3), 223-236.

Dillard, C. (2000). The substance of things hoped for, the evidence of things not seen: Examining an endarkened feminist epistemology in educational research and leadership. Qualitative Studies in Education, 13(6), 661-681.

Erickson, F. (1986). Qualitative methods in research on teaching. In M. C. Wittrock (Ed.), Handbook of research on teaching (3rd ed., pp. 119-161). Thousand Oaks, CA: Sage Publications.

Ghiso, M.P. (2016). The laundromat as the transnational local: Young children's literacies of interdependence. Teachers College Record, 118, 1-46.

Goodwin, A.L. (2010). Curriculum as colonizer: (Asian) American education in the current U.S. context. Teachers College Record, 112(12), 3102-3138.

Harper, S. R. (2013). Am I my brother's teacher? Black undergraduates, racial socialization, and peer pedagogies in predominantly white postsecondary contexts. Review of Research in Education, Vol. 37, 183-211.

Harper, S. R. (2015). Black male college achievers and resistant responses to racist stereotypes at predominantly white colleges and universities. Harvard Educational Review, 85(4), 646-674.

Harper, S. R., Davis, R. J., Jones, D. E., McGowan, B. L., Ingram, T. N., \& Platt, C. S. (2011). Race and racism in the experiences of Black male resident assistants at predominantly White universities. Journal of College Student Development, 52, 180-200.

Kemmis, S., \& McTaggart, R. (2005). Participatory action research. In N. K. Denzin \& Y.S. Lincoln (Eds.), The SAGE handbook of qualitative research (3rd ed., pp. 559-603). Thousand Oaks, CA: Sage.
Kristoff, N. (2016, July 23). Is Donald Trump racist? The New York Times. Retrieved from http:// www.nytimes.com/2016/07/24/opinion/ sunday/is-donald-trump-a-racist.html

Lee, S. (2009). Unraveling the "model minority" stereotype: Listening to Asian American youth (2nd ed.). New York: Teachers College Press.

Lee, S. J. (2005). Up against whiteness: Race, school, and immigrant youth. New York: Teachers College Press.

Lorde, A. (2007). Sister outsider: Essays and speeches by Audre Lorde. Berkeley, CA: Crossing Press.

Maxwell, J.A. (2013). Qualitative research design: An interactive approach. (3rd ed.). Thousand Oaks, CA: Sage.

Mohanty, S. (1997). Literary history and the claims of history: Postmodernism, objectivity, multicultural politics. Ithaca, NY: Cornell University Press.

Moya, P. (2000). Postmodernism, "realism," and the politics of identity. In P. Moya \& M. Hames-Garcia (Eds.), Reclaiming identity: Realist theory and the predicaments of postmodernism (pp. 67-101). Berkeley, CA: University of California Press.

Paris, D. (2011). "A friend who understands fully": Notes on humanizing research in a multiethnic youth community. International Journal of Qualitative Studies in Education, 24(2), 137-149.

Paris, D., \& Winn, M. T. (Eds.). (2014). Humanizing research: Decolonizing qualitative inquiry with youth and communities. Thousand Oaks, CA: Sage.

Petty, T. (2014). Motivating first-generation students to academic success and college completion. College Student Journal, 48(2), 257-264.

Player, G., Ngo, L., \& Campano, G. (2016). The community researchers project: The role of care in critical work. In G. Campano, M.P. Ghiso, \& B. Welch (Aus.), Partnering with immigrant communities: Action through literacy (pp. 103-114). New York: Teachers College Press. 
Simon, R., Campano, G., Broderick, D., \& Pantoja, A. (2012). Activist methodologies: Theorizing literacy from practice. Special issue on research methodologies, English: Practice and Critique, 11(2), 5-24.

Smith, L.T. (2012). Decolonizing methodologies: Research and indigenous peoples (2nd ed.). London: Zed Books.

Strauss, A., \& Corbin, J. (1998). Basics of qualitative research: Grounded theory procedures and techniques. Newbury Park, CA: Sage Publications.

Terenzini, P. T., Rendon, L. I., Upcraft, M. L., Millar, S. B., Allison, K. W., Gregg, P. L., et al. (1994). The transition to college: Diverse students, diverse stories. Research in Higher Education, 35(1), 57-73.
U.S. Census Bureau. (2011). 2006-2010 American community survey 5-year estimates. Washington, DC: Author. Retrieved from http://www.census.gov/acs/www/data _documentation/2010_release/

U.S. Census Bureau. (2012). The Asian population: 2010, Census 2010 brief. Washington, DC: Author. Retrieved from http://www.census. gov/prod/cen2010/briefs/c2010br-11.pdf

Yee, M., Mostafa, K., \& Campano, G. (2016). Participatory research with parents: Mobilizing social capital to support children's education. In G. Campano, M. P. Ghiso, \& B. J. Welch (Aus.), Partnering with immigrant communities: Action through literacy (pp. 39-53). New York: Teachers College Press.

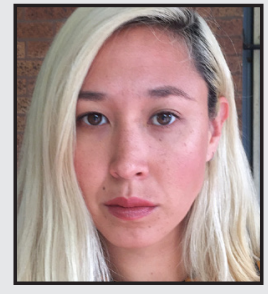

Grace D. Player is a doctoral candidate in the Reading/ Writing/Literacy program at the University of Pennsylvania's Graduate School of Education. Alongside a multilingual and multicultural community in South Philadelphia and her Penn GSE research team, she co-investigates how youth and families use a richness of literacy and language practices to research their worlds, name their experiences, and advocate for their rights. Her dissertation work, which is situated within this community, inquires into the genius of girls of color who use a complex web of literacies to better understand the issues they name as most important and to advocate, in coalition and through difference, for justice. 


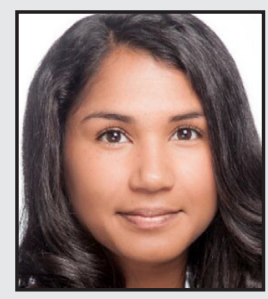

Victoria S. Gill, a former middle school English teacher, is currently a doctoral student in the Reading/Writing/Literacy program at the University of Pennsylvania's Graduate School of Education. She is also a Learning Fellow at the Weingarten Learning Resources Center researching and supporting various students with their diverse academic needs. Her research interests include how students' and teachers' intersectional and multiple identities, including race, gender, religion and sexuality, affect literacy, in/out of school relationships, and pedagogy.

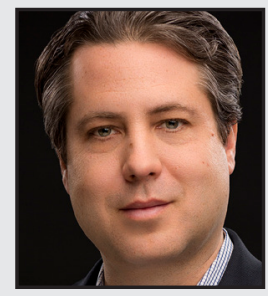

Gerald Campano is Associate Professor and Chair of the Reading/Writing/Literacy Program at the University of Pennsylvania's Graduate School of Education. His scholarship focuses on practitioner research, immigrant students and families, critical literacy, identity, and university-community partnerships. Gerald is a Carnegie Scholar and the recipient of the David H. Russell Award for Distinguished Research in the Teaching of English from NCTE for his book Immigrant Students and Literacy: Reading, Writing, and Remembering. He has published in a range of venues, including Harvard Educational Review, Educational Leadership, Research in the Teaching of English, and Review of Research in Education. 